\title{
Correlation between Hand Grip Strength and Core Muscle Activation in Physical Therapists of Gujarat
}

\author{
Disha Vallabhbhai Solanki ${ }^{1}$, Neela Soni ${ }^{2}$ \\ ${ }^{1} \mathrm{PhD}$ Scholar in Gujarat University, I/C Lecturer, Government Spine Institute and Physiotherapy College, \\ Ahmedabad \\ ${ }^{2} \mathrm{Ph}$. D. Guide in Gujarat University and Academic Director, SKUM College of Physiotherapy, Ahmedabad.
}

Corresponding Author: Disha Vallabhbhai Solanki

\begin{abstract}
Background: Hand grip strength is of great significant parameter in evaluation of hand function and it is most reliable clinical assessment tool of human strength. It is very useful in various professions where people must work with their hand, like physiotherapy. The core serves at the center of functional kinetic chain in alternative medicine world; the core has been referred to as the "powerhouse", the foundation or engine of all limb movements. So the purpose of this study is to find out correlation between hand grip strength and core muscle activation in physical therapists of age group 18 to 25 .

Methods: Two hundred physical therapists volunteered to participate in this study were assessed for height, weight, BMI, the hand grip strength of the dominant hand and the non-dominant hand and core muscle activation. The hand grip strength was assessed with Jamar dynamometer and the core muscle activation was assessed with Pressure Biofeedback Unit.

Results: Pearson's correlation coefficient was used. The results of this study shows that there was weak positive correlation $(\mathrm{r}=0.42)$ between the hand grip strength of dominant hand and non-dominant hand with core muscle activation.
\end{abstract}

Conclusion: This study shows weak correlation between the hand grip strength with core muscle activation.

Keywords: Hand grip strength, Hand dynamometer, Core muscle strength, Pressure Biofeedback Unit

\section{INTRODUCTION}

The power of hand grip is a product of forceful flexion of all finger joints with maximum voluntary force that subject is able to exert under normal bio kinetic conditions. ${ }^{1}$ Hand grip strength is frequently used as an indicator of by and large physical strength, hand and forearm muscle performance, and as a functional index of nutritional status and physical performance. 1,2 It is accepted that grip strength provide an objective index for the functional integrity of upper extremity. It is most accepted reliable and valid tool to determine effectiveness of treatment strategies. ${ }^{3}$
The core is a functional hub of the kinetic chain in alternative medicine world; the core has been referred to as the "powerhouse", the foundation or engine of all limb movements. ${ }^{4}$ Hedrick A.(2000) All movements of the body either originates in or are coupled through the trunk, and this coupling action is created by a strong core. ${ }^{1,5}$ Core stability is important for efficient biomechanical function to maximise force generation and minimise joint loads in all types of activities ranging from running to throwing. ${ }^{6}$ Core has been linked through a kinetic chain formed with lower and upper extremities which makes them responsible for all forms of functions 
and performance tasks. The stronger core will help to maximize upper and lower extremity function. ${ }^{7}$

A variety of occupational pulling and pushing tasks as well as several everyday functions and sporting activities demand the controlled use of abdominal and trunk muscles while working with the upper limbs. ${ }^{8}$ Physiotherapy is a kind of profession in which the physical therapist has to deal with a greater amount of manual work as well as exercises in various upright positions whole day. Several manipulations manual therapy demamd the controlled use of abdominal and back muscles while working with upper limbs. specified the demands of this occupation, it can be anecdotal that it challenges core muscles and hand grip strength.

Dr. P. Sathya (2017) found in her study concluded that there was weak correlation between dominant and nondominant hand grip strength with core muscle strength. There are many studies done on the grip strength and the core muscle activation separately but there are very few studies done on correlation between the grip strength and the core muscle activation, hence the need of this study was to find the correlation between the grip strength and the core muscle activation in physical therapists.

\section{OBJECTIVE:}

The purpose of the study is to determine the correlation between hand grip strength (in dominant hand and nondominant hand) and core muscle strength in Physical therapist.

\section{MATERIALS AND METHOD}

$\square$ Study design - An Observational study

- Sample size -200 subjects

$\square$ Sampling method - Convenient sampling

$\square$ Nature of subject - Physical therapists/students with age group between 18-25 years were taken.
- Study setting - Physiotherapy colleges of Ahmedabad

- Inclusion criteria :-

- Physical therapists between 18-25 years of age.

- Both male and female subjects \{ Rt hand dominant subjects Handedness was determined by Edinburgh inventory Questionnaire (1971) $\}^{9}$

口 Exclusion criteria:-

- Musculoskeletal pain in upper limb

- Trauma to the lumbar spine and upper limb

- Neurological disorders that affect upper limb function and spine functions.

- R.O.M deficit in upper extremity

- Subjects pursuing fitness training

- Cancer

- Recent upper limb, Lumbar spine and Abdominal surgery

o Pregnancy

- Severe kyphosis or scoliosis

- Spinal stenosis

- Nerve root entrapment

- Mentally challenged

- Low back pain - subjects who has missed work due to back pain in preceding six months

Ethical Approval:-

The ethics approval was obtained from Institutional Ethics Committee of B.J. Medical College and Civil Hospital, Ahmedabad with ethics approval number GSIIESC/01/17

\section{Procedure:-}

Demographic data of the subjects such as age, height and weight were noted and BMI was calculated. Informed written consent was signed. Familiarization was done with the technique of the test performance was explained prior to the test. Hand Grip Strength Test -

A Hydraulic Hand Dynamometer with adjustable grip was calibrated and used. The standard position guidelines recommended by American society of hand therapists (ASHT) was used for the measurement of grip strength. The positioning of the subject while evaluation 
was seated in a chair without armrests, with the feet resting entirely on the ground and the hip against the back of the chair. Shoulder adducted, elbow flexed at 90 degrees, forearm in neutral position, wrist between 0 -30 degrees of extension and 015 degrees of ulnar deviation. The participants were instructed to hold the dynamometer and asked to use maximum force of hand squeeze around the dynamometer. The test was done on Right limb and then the Left limb. Three trials were performed, with 15 seconds rest provided between each trial. Average of the three trials was taken as final reading.

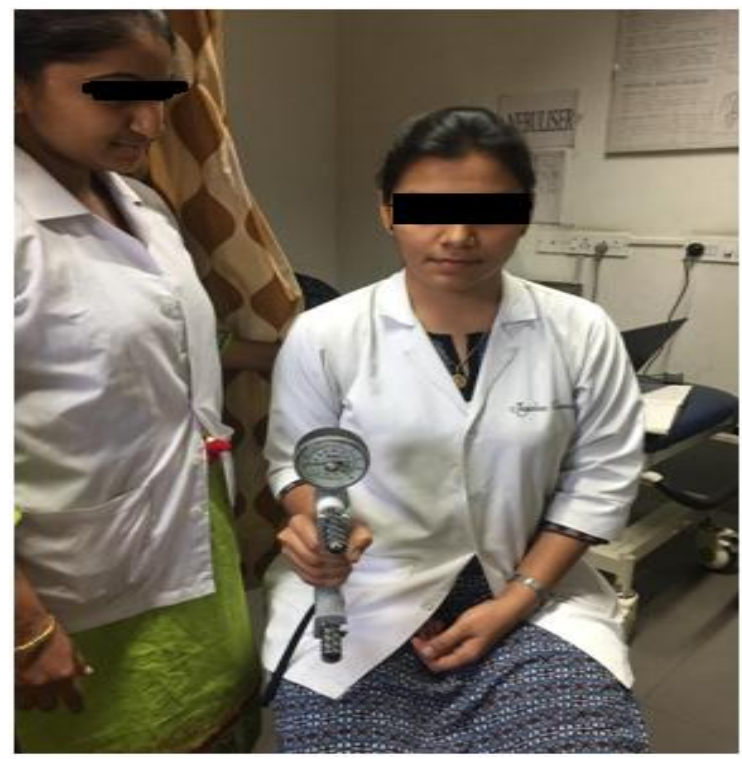

Figure. 1: Test position front view

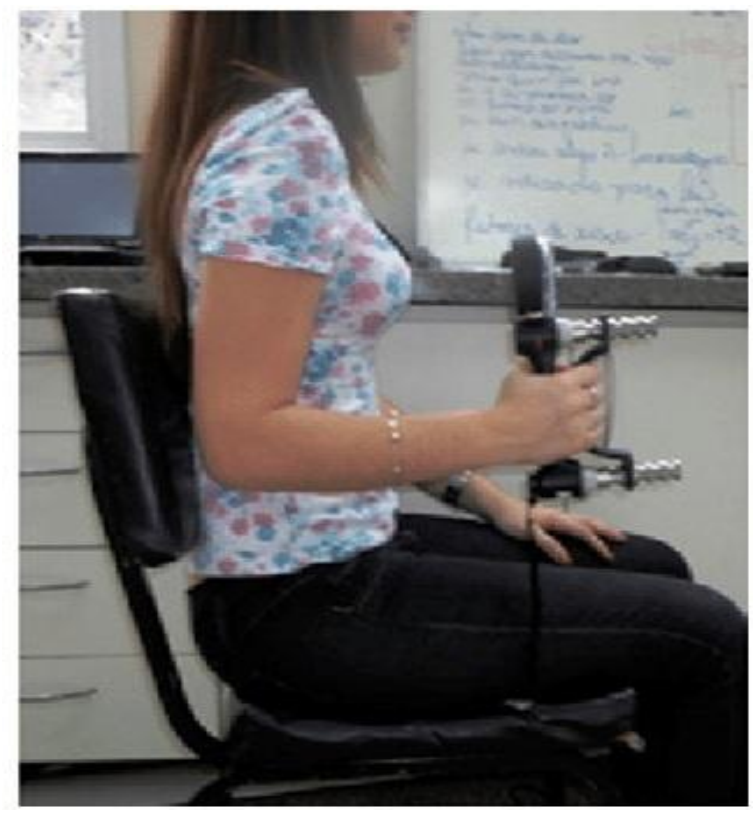

Figure. 2: Test position side view
The core muscle strength - was measured by using Pressure Biofeedback Unit by the following procedure:-

The abdominal draw in test will be performed with the subject in a prone lying position, and the Pressure Biofeedback Unit will be utilized to evaluate the ability of the subject to perform this abdominal isolation test. The Pressure Biofeedback Unit will be placed under the abdomen with the navel in the centre. ${ }^{9,10}$ The Pressure Biofeedback Unit will then be inflated to $70 \mathrm{mmHg}$ and will be allowed to stabilize, allowing for detection of fluctuations in pressure due to normal breathing, which may be approximately $2 \mathrm{mmHg}$ for each inhalation and exhalation. Subjects will be instructed to perform an abdominal contraction. The instructions are given to breathe in and out and then, without breathing in, to slowly draw in the abdomen so that it lifts up off the pad, keeping the spinal position steady. ${ }^{10,11}$ Deep inspiration is to be avoided. Then pressure change will be noted. The patient will be required to hold the contraction for $10 \mathrm{sec}$. The same procedure will be repeated for three times and pressure changes are noted and the average of the three repetitions will be used for analysis.

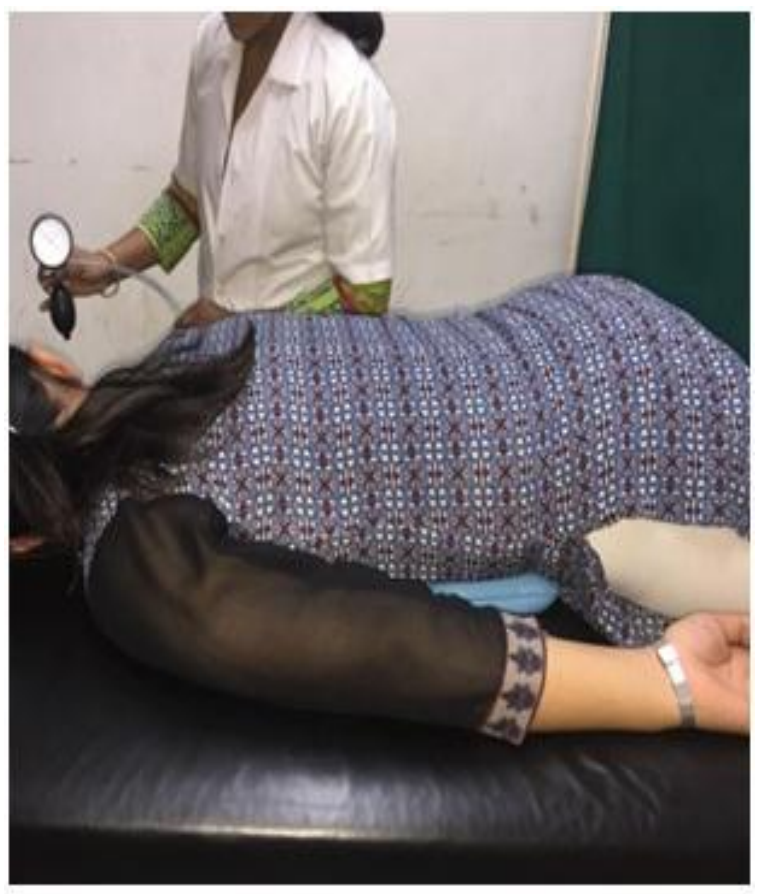

Figure.3: Core muscle activation with Pressure Biofeedback Unit 
Disha Vallabhbhai Solanki et.al. Correlation between hand grip strength and core muscle activation in physical therapists of Gujarat.

\section{Statistics}

The Pearson correlation coefficient was used to find out correlation between hand grip strength and core muscle activation. The Table 1 shows mean, standard deviation and ranges for dominant hand grip strength, non- dominant hand grip strength and core muscle activation score of 18-25 years of aged physical therapists.

Table 1: The mean and standard deviation of the dominant hand grip strength, non dominant hand grip strength and core muscle activation.

\begin{tabular}{|l|l|l|l|}
\hline & $\begin{array}{l}\text { Dominant hand grip strength } \\
(\mathbf{k g})\end{array}$ & $\begin{array}{l}\text { Non-dominant hand grip strength } \\
(\mathbf{k g})\end{array}$ & $\begin{array}{l}\text { Core muscle activation } \\
(\mathbf{m m} \text { Hg) }\end{array}$ \\
\hline N & 200 & 200 & 200 \\
\hline Mean & 25.82 & 25.11 & 5.49 \\
\hline Standard Deviation & 7.14 & 7.04 & 1.64 \\
\hline $95 \%$ Confidence Interval & $24.83-26.81$ & $24.13-26.39$ & $5.27-5.72$ \\
\hline
\end{tabular}

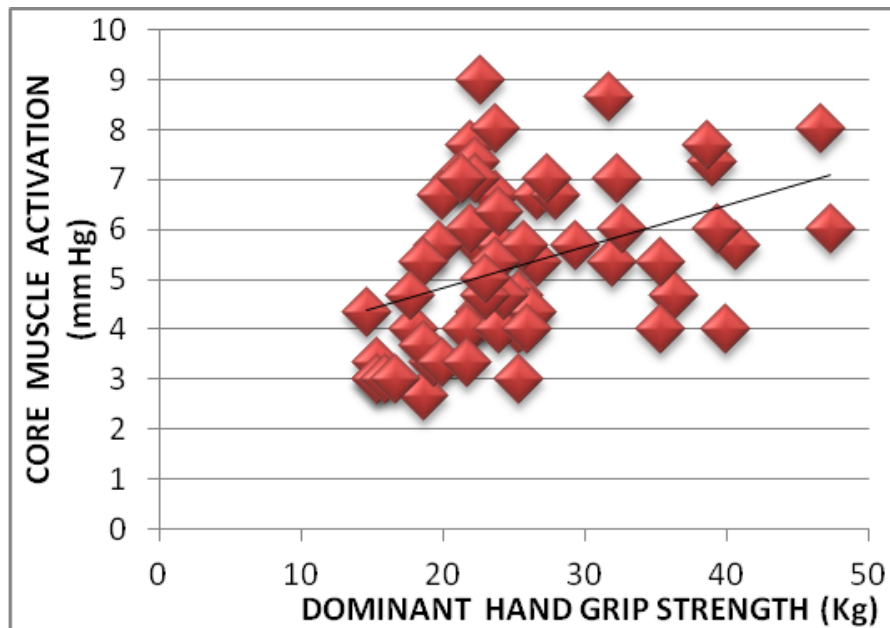

Figure 4: Scatter Diagram showing correlation between Dominant Hand Grip Strength and Core Muscle Activation

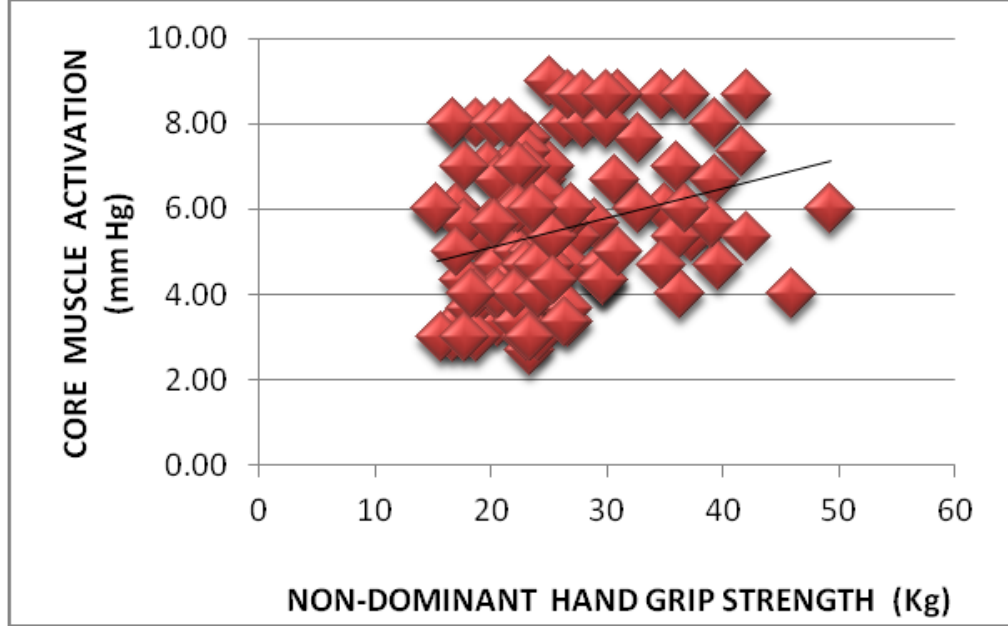

Figure 5: Scatter Diagram showing correlation between Non-dominant Hand Grip Strength and Core Muscle Activation

\section{RESULTS}

Scattered diagram shows $(r-0.42)$ weak positive correlation between Dominant and Non-dominant hand grip strength and core muscle activation.

\section{DISCUSSION}

In normal human movement postural reflects are organized well ahead in anticipation of movements or perturbations to balance. Transverse abdominis (TA) is one of the many trunk muscles that take part in this anticipatory organization. ${ }^{13,14}$

"Hollowing in" of the abdomen creates isolated activation of (TA) which run parallel with internal oblique. The TA and multified have been shown to contract 30 seconds before movement of shoulder. ${ }^{4}$ 
The core is anatomically and biomechanically connected to the shoulders as it has a major muscle link with the shoulder muscles which include the fascia that connect Latissimus Dorsi and middle and lower fibres of Trapezius. ${ }^{12,15}$ This connection has been proved in the study where EMG analysis was done to monitor recruitment pattern of core muscles during resisted isometric exercises of shoulders. The study demonstrated that all the shoulder exercises which were done with resistance had positive activity of core muscles. Studies reveal that core strength has a positive and good correlation with upper extremity functions in tennis players, golfers and cricketers. ${ }^{15,16}$

In this study, BMI matched physiotherapists were selected in the age group of 18-25 years. From this study it shows weak positive correlation between Dominant and Non-dominant hand grip strength and core muscle activation in $18-$ 25 years of age. The finding of this study was consistent with a study done by $\mathrm{Dr}$ Sathiya et al. in 2017 in cricket players ${ }^{2}$.

Findings of this study reveals mean range of Dominant hand grip strength lies between 18.68-32.96 kg. Result of this study is consistent with study done by Bhoomika B.et al 2015 in physical therapist using SAEHANS SH®5001 hydraulic handheld dynamometer. Findings of this study also reveals mean range of core muscle activation lies between 3.85-7.13 $\mathrm{mmHg}$ which is similar to study done by Sheshna R. et al (2015) ${ }^{11}$.

\section{CONCLUSION}

This study concludes that there is weak correlation between dominant and non-dominant hand grip strength with core muscle activation.

Limitations: Small sample size.

Acknowledgement: None

Conflict of Interest: None

\section{Source of Funding: None}

\section{Ethical Approval: Approved}

\section{REFERENCES}

1. Massy-Westropp, N., Rankin, W., Ahern, M., Krishnan, J., \& Hearn, T. C. (2004). Measuring grip strength in normal adults: reference ranges and a comparison of electronic and hydraulic instruments. The Journal of hand surgery, 29(3), 514-519.

2. Dr. Sathya P, Sabina Dudekula Correlation between Hand Grip Strength and Core Muscle Strength in Cricket Players International journal of science and research 2017 March ;186-189

3. Bohannon RW. Reference values for extremity muscle strength obtained by handheld dynamometry from adults aged 20 to 79 years. Archives of physical medicine and rehabilitation. 1997 Jan 1;78(1):26-32.

4. Brahmbhatt B, Vyas D, Thakrar G. A Comparative Study on Dominant Hand Grip Strength in Physical Therapists v/s NonPhysical Therapists in Ahmedabad. Website: www. ijpot. com. 2015 Oct;9(4): 159.

5. Hedrick A. Training the trunk for improved athletic performance. Strength \& Conditioning Journal. 2000 Jun 1;22(3):50.

6. Sung D, Park S, Kim S, Kwon M, Lim Y. Effects of core and non-dominant arm strength training on drive distance in elite golfers. Journal of Sport and Health Science. 2016; 5(2):219-225.

7. Kim J, Lee DY, Yu J, Kim J, Hong J. The influence of abdominal muscles on shoulder isometric muscular strength. Indian Journal of Science and Technology. 2015; 8(25)

8. Akuthota V, Nadler SF. Core strengthening1. Archives of physical medicine and rehabilitation. 2004 Mar 1;85:86-92.

9. Tarnanen SP, Siekkinen KM, Häkkinen AH, Mälkiä EA, Kautiainen HJ, Ylinen JJ. Core muscle activation during dynamic upper limb exercises in women. The Journal of Strength \& Conditioning Research. 2012 Dec 1;26(12):3217-24.

10. Oldfield RC. The assessment and analysis of handedness: the Edinburgh inventory. Neuropsychologia. 1971 Mar 1;9(1):97-113

11. Rathod S, Paneri H, Solanki D. A Study to measure the endurance capacity of 

therapists of Gujarat.

Transversus Abdominis in normal individuals. Indian Journal of Physiotherapy and Occupational Therapy-An International Journal. 2015;9(1):39-43.

12. Aly SM, El-Mohsen AM, El Hafez SM. Effect of six weeks of core stability exercises on trunk and hip muscles' strength in college students. International Journal of Therapies and Rehabilitation Research. 2017;6(2):9.

13. Hodges P, Cresswell A, Thorstensson A. Preparatory trunk motion accompanies rapid upper limb movement. Experimental brain research. 1999 Jan 1;124(1):69-79.

14. Hwang YI, Park DJ. Comparison of abdominal muscle activity during abdominal drawing-in maneuver combined with irradiation variations. Journal of exercise rehabilitation. 2017 Jun;13(3):335.
15. Yoon MR, Choi HS, Shin WS. Effects of the abdominal drawing-in maneuver and the abdominal expansion maneuver on grip strength, balance and pulmonary function in stroke patients. The Journal of Korean Physical Therapy. 2015 Jun 30;27(3):14753.

16. Gurudut P, Rayani M, Tar N. A Clinical Trial to Study the Effect of 5 Week Core Strengthening Protocol on Shoulder Strength in Young Obese Individuals. JMSCR. 2017; 5(3).

How to cite this article: Solanki DV, Soni N. Correlation between hand grip strength and core muscle activation in physical therapists of Gujarat. Int J Health Sci Res. 2021; 11(5):82-87. DOI: https://doi.org/10.52403/ijhsr.20210512 